\title{
Retraction
}

The article titled "Risk of cardiovascular disease among diabetic patients in rural population of Central India" by Singh PS published in International Journal of Research in Medical Sciences 2017;5(4):1563-70, DOI: http://dx.doi.org/10.18203/2320-6012.ijrms20171266 is retracted.

After the publication of the above article, one of the publishers reported that a large part of the text is plagiarized from a similar article published in Journal of Anthropology, Volume 2014, Article ID 421439, 9 pages, http://dx.doi.org/10.1155/2014/421439 (Mary Grace Tungdim, T. Ginzaniang, G. Poufullung Kabui, Deepali Verma, Satwanti Kapoor. Risk of Cardiovascular Disease among Diabetic Patients in Manipur, Northeast India). We contacted the author who could not satisfactorily respond to our queries. Since the author could not satisfactorily defend his paper and contravened the declaration he made while submitting his manuscript, it was decided to retract the article from International Journal of Research in Medical Sciences and not to consider any manuscript submitted by him in future. 


\title{
Original Research Article
}

\section{Risk of cardiovascular disease among diabetic patients in rural population of Central India}

\author{
Prem S. Singh*, K. S. Zafar, Manoj Kumar, Sudhir K. Yadav
}

Department of Medicine, Uttar Pradesh University of Medical Sciences, Saifai, Etawah, Uttar Pradesh, India

Received: 26 January 2017

Accepted: 04 March 2017

\section{*Correspondence:}

Dr. Prem S. Singh,

E-mail: premshanker0354@gmail.com

Copyright: (C) the author(s), publisher and licensee Medip Academy. This is an open-access article distributed under the terms of the Creative Commons Attribution Non-Commercial License, which permits unrestricted non-commercial use, distribution, and reproduction in any medium, provided the original work is properly cited.

\section{ABSTRACT}

Background: Incidence and prevalence of diabetes is on surge day by day and increased longevity of diabetic patients put them at higher risk of chronic complications of hyperglycemia. Of these complications, atherosclerotic cardiovascular diseases (CVD) are of utmost importance and atherosclerotic cardiovascular diseases are the major cause of premature mortality in patients with type 2 diabetes as well. Regional variation of risk factors and sociocultural diversity of Indian population create a significant difference in atherosclerotic risk among the diabetic population across the country. There is a significant gap in the knowledge of CVD epidemiology and associated risk factors among the Indian population especially among the rural population. The objective of this study was to assess cardiovascular risk among diabetic patients of rural central India.

Methods: The present cross-sectional study included 160 diabetic patients (78 males and 82 females) aged 35-75 years from the villages of district Etawah of UP, Central India. Sex-specific Framingham general cardiovascular risk prediction equations were used to calculate the 10years risk for cardiovascular disease. The probable risk factors were determined by cross-tabulation of cardiometabolic parameters with the 10-year cardiovascular risk level.

Results: Males were found to be at higher risk of developing CVD in the future as compared to females with a discernible accumulation of adyerse cardiovascular risk factors among them. $38.75 \%$ patients were at high risk, $37.50 \%$ at moderate risk and $23.75 \%$ at low risk for developing CVD in the next 10 years. Systolic blood pressure, total cholesterol, triglyceride and smoking contributed significantly to high degree of cardiovascular risk. Presence of cardiovascular risk factors among diabetic patients at diagnosis accentuates the need of intensive management of cardiovascular complications taking into consideration the traditional dietary pattern of the rural population.

Conclusions: Both diabetes and CVD have common genetic and environmental antecedents. Furthermore, insulin resistance preceding long before the diagnosis of diabetes enhances atherogenic risk profile and has been delineated as a potential cause for subsequent increased risk of CVD among diabetic patients. There is need of intensive management of cardiovascular risk factors among diabetic individuals. Therefore, there is a need of a comprehensive study design which includes various factors (biological, sociodemographic and genetic) which directly or indirectly influence the disease incidence especially in a country (India) with diverse ethnic population.

Keywords: Cardiovascular risk, Coronary artery disease, Diabetes

\section{INTRODUCTION}

Changes in the human environment, behavior and lifestyle are contributing to the upsurge in the incidence of diabetes. However, better management has resulted in a longer survival of patients with diabetes, but it is accompanied by long-term chronic complications due to hyperglycemia. ${ }^{1}$ Individuals with diabetes most often die of cardiovascular disease (CVD) rather than from a cause uniquely related to diabetes, such as ketoacidosis or 
hypoglycemia. ${ }^{2,3}$ Diabetic patients have a twofold to sixfold higher incidence of cardiovascular disease than nondiabetic population. ${ }^{3,4}$ Furthermore, diabetic patients with CVD sustain a worse prognosis for survival than CVD patients without diabetes and their quality of life also depreciates. Therefore, diabetes has been considered as having a risk equivalent to a nondiabetic patient with preexisting heart disease. ${ }^{4}$ Identification of patients at risk for CVD could facilitate the prevention or retardation of cardiovascular events. ${ }^{3-5}$

Lifetime risk estimates provide a simple conceptual basis for estimating the absolute risk of developing disease over the remaining lifespan. ${ }^{4-6}$ Presence of several risk factors among diabetic patients suffering from cardiovascular disease stresses on the assessment of the individual's total burden of risk rather than on the level of any particular risk factor. ${ }^{6,7}$ Several multivariate risk prediction algorithms have been developed to predict future CVD risk but their use has lagged in primary care. ${ }^{7,9,10}$ Sex-specific Framingham risk prediction model however has been incorporated in the report on detection, evaluation and treatment of high blood cholesterol in adults, adult treatment panel III (NCEP ATP-III). ${ }^{10-12}$

In India, regional variation has been reported in cardiovascular disease incidence and mortality. However, there lies a significant gap in the knowledge of CVD epidemiology and associated risk factors among the Indian population especially among the rural India population. The increasing prevalence of cardiovascular disease and diabetes emphasizes the need to bridge the gap by considering the distinct sociocultural, biological and ethnic diversity of the Indian population. The purpose of our study was to assess the cardiovascular risk among type 2 diabetic patients of rural central India, based on Framingham prediction equations and to identify the associated risk factors.

\section{METHODS}

The present cross-sectional study included 160 diabetic patients ( 78 males and 82 females) aged $35-75$ years who were outpatients of Uttar Pradesh University of medical sciences Saifai, Etawah, Uttar Pradesh, India which is located in Saifai village of Etawah district. The subjects were patients diagnosed as suffering from diabetes by the doctors and whose fasting glucose (FG) level was $\geq 126 \mathrm{mg} / \mathrm{dl} .{ }^{12,13}$ Patients suffering from any cardiovascular disease were excluded from the study. The purpose of the study was explained to all the subjects prior to data collection. Informed written consent was obtained from each subject who volunteered for the study.

The anthropometric measurements were taken using standard techniques of Weiner and Lourie. ${ }^{13,14}$ Standing height was measured to the nearest 0.1 centimetre with fixed stadiometer. Body weight was measured in kilograms with a weighing scale to the nearest 0.5 kilogram. Waist and hip circumferences were recorded to the nearest $0.1 \mathrm{~cm}$ using a flexible steel tape. Body mass index (BMI) was derived by dividing the body weight by the height squared $\left(\mathrm{kg} / \mathrm{m}^{2}\right)$. Waist hip ratio (WHR) and waist height ratio (WHtR) were calculated. The patients were classified on the basis of body mass index (BMI) using WHO classification. ${ }^{14-16}$ Central obesity was assessed by using WC (waist circumference), WHR and WHtR standard criteria. ${ }^{15-17}$

Blood pressure, systolic (SBP) as well as diastolic (DBP), was recorded using anaeroid sphygmomanometer and stethoscope as recommended by the American Heart Association. ${ }^{18,19}$ Patients were stratified into hypertensive and prehypertensive based on the definition of the Seventh Report, Joint National committee on prevention, detection, evaluation, and treatment of high blood pressure. ${ }^{18-20}$

The patients were referred to a laboratory where intravenous blood was drawn by trained technician after a fasting period of at least 10 hours to estimate the value of fasting glucose (FG), total cholesterol (TC), triglyceride (TG), high density lipoprotein (HDL) and low density lipoprotein (LDL) From the measurements of TC and HDL, the TC/HDL ratio was calculated. Dyslipidemia was defined by the presence of more than one abnormal serum lipid concentration. Subjects were classified into risk categories for each lipoprotein and TC/HDL ratio based on the National Cholesterol Education Program(NCEP) andAdult Treatment Panel III(ATPIII) guidelines. ${ }^{10-12}$ The uncontrolled glycemia was defined as having fasting blood glucose level $>126 \mathrm{mg} / \mathrm{dL} .{ }^{19-21}$

The 10-year risk of cardiovascular disease (CVD) was assessed by sex-specific general risk prediction equations derived by D'Agostino Sr. et al from Framingham Heart Study. ${ }^{20-22}$ Since in the original study the upper age limit of the cohort was 75 years, subjects aged 76 years and above were excluded in the present study to avoid erroneous risk score estimation.

The different variables included in the scoring were age, systolic blood pressure, treatment for hypertension, smoking status, diabetes status, total cholesterol and HDL Tobacco intake and smoking status of the subjects were obtained using self-administered questionnaire. Based on the total risk score calculated, subjects were categorized to be at high $(>20 \%)$, moderate $(10-20 \%)$, and low $(<10 \%)$ risk of cardiovascular disease. ${ }^{10-12}$

Statistical analysis of data was performed using the Statistical Package for social sciences version 21.0. categorical variables were expressed as absolute number and percentage while continuous variables were expressed as mean and standard deviation (SD). Correlations between different variables were calculated using Pearson's correlation method and values were expressed as correlation coefficient(r). A p value of less than 0.05 was considered significant. 


\section{RESULTS}

Descriptive values for anthropometric and clinical characteristic of diabetic patients are given in table- 1 as follows:

Table 1 describes the baseline data of the diabetic patients Mean age, onset age and duration for diabetes were $56.4 \pm 9.26$ years, $50.0 \pm 9.42$ years, and 5.5 \pm 5.02 years respectively with no gender differences. Males were significantly taller $(164.8 \pm 7.61 \mathrm{~cm})$ and heavier
$(62.7 \pm 9.24 \mathrm{~kg})$ than females (height- $153.9 \pm 8.42 \mathrm{~cm}$, weight $-55.8 \pm 10.37 \mathrm{~kg}$ ) but the latter had higher BMI $(24.3 \pm 4.77 \mathrm{~kg} / \mathrm{m} 2)$ as compared to males $(22.5 \pm 2.86 \mathrm{~kg} / \mathrm{m} 2)$. Mean values for central adiposity (WC and WHtR) were also significantly higher among females than males, while the cardiometabolic risk factors, SBP $(136.7 \pm 16.71 \mathrm{mmHg})$, fasting glucose $(188.3 \pm 89.10 \mathrm{mg} / \mathrm{dL})$ and estimated 10-years cardiovascular risk score $(27.5 \pm 17.23)$ were significantly higher among males than females (124.3 \pm 13.44 , $148.7 \pm 84.67$ and $19.9 \pm 8.69$ resp).

Table 1: Descriptive value for anthropometric and clinical characteristic of diabetic patients from rural central India.

\begin{tabular}{|llllll|}
\hline Variable & $\begin{array}{l}\text { Total }(\mathbf{N = 1 6 0}) \\
\text { Mean } \pm \text { SD }\end{array}$ & $\begin{array}{l}\text { Male }(\mathbf{N = 7 8}) \\
\text { Mean } \pm \text { SD }\end{array}$ & $\begin{array}{l}\text { Female }(\mathbf{N}=82) \\
\text { Mean } \pm \text { SD }\end{array}$ & $\begin{array}{l}\text { t-value } \\
\text { p- } \\
\text { value }\end{array}$ \\
\hline Age (years) & $56.4 \pm 9.26$ & $56.6 \pm 8.68$ & $56.3 \pm 9.87$ & 0.136 & 0.894 \\
\hline Age of onset (years) & $50.0 \pm 9.42$ & $50.4 \pm 9.35$ & $49.6 \pm 9.64$ & 0.166 & 0.875 \\
\hline Duration (years) & $5.5 \pm 5.02$ & $5.4 \pm 4.87$ & $5.6 \pm 5.21$ & 0.125 & 0.669 \\
\hline Height $(\mathrm{cm})$ & $159.1 \pm 10.96$ & $164.8 \pm 7.61$ & $153.9 \pm 8.42$ & 8.357 & $<0.001$ \\
\hline Weight $(\mathrm{kg})$ & $59.1 \pm 10.08$ & $62.7 \pm 9.24$ & $55.8 \pm 10.37$ & 2.230 & 0.029 \\
\hline Body mass index (BMI: kg/m $)$ & $23.5 \pm 4.15$ & $22.5 \pm 2.86$ & $24.3 \pm 4.77$ & 2.979 & 0.004 \\
\hline Waist circumference (WC: $\mathrm{cm})$ & $85.9 \pm 9.02$ & $84.8 \pm 7.34$ & $87.06 \pm 10.24$ & 1.328 & 0.184 \\
\hline Waist hip ratio (WHR) & $0.95 \pm 0.06$ & $0.96 \pm 0.06$ & $0.94 \pm 0.06$ & 1.478 & 0.144 \\
\hline Waist height ratio (WHtR) & $0.53 \pm 0.69$ & $0.51 \pm 0.05$ & $0.56 \pm 0.06$ & 6.182 & $<0.001$ \\
\hline Systolic blood pressure (SBP: $\mathrm{mmHg})$ & $130.3 \pm 15.60$ & $136.7 \pm 16.71$ & $124.3 \pm 13.44$ & 2.485 & 0.016 \\
\hline Diastolic blood pressure (DBP:mmHg) & $85.0 \pm 10.82$ & $86.0 \pm 12.58$ & $84.1 \pm 8.88$ & 0.852 & 0.398 \\
\hline Cholesterol (mg/dL) & $184.0 \pm 42.49$ & $175.6 \pm 32.58$ & $191.9 \pm 49.62$ & 1.313 & 0.194 \\
\hline Triglyceride (mg/dL) & $177.1 \pm 60.51$ & $181.0 \pm 63.78$ & $175.7 \pm 57.72$ & 0.506 & 0.612 \\
\hline LDL (mg/dL) & $48.8 \pm 14.78$ & $66.6 \pm 31.97$ & $88.4 \pm 42.41$ & 2.35 & 2.352 \\
\hline HDL (mg/dL) & $77.8 \pm 38.82$ & $48.9 \pm 16.20$ & $48.7 \pm 13.52$ & 0.056 & 0.954 \\
\hline Fasting glucose level (mg/dL) & $167.7 \pm 88.97$ & $188.3 \pm 89.10$ & $148.7 \pm 84.67$ & 2.244 & 0.126 \\
\hline Framingham risk score (FRS) & $21.0 \pm 15.25$ & $27.5 \pm 17.23$ & $14.9 \pm 8.69$ & 4.845 & $<0.001$ \\
\hline
\end{tabular}

Table 2: Sex-wise distribution of diabetic patients in different categories of the cardiovascular risk factors.

\begin{tabular}{|c|c|c|c|c|c|c|}
\hline Variables & Categories & Overall & Male & Female & Chi-square & p-value \\
\hline \multirow{3}{*}{ BMI } & Underweight & $8.12(13)$ & $7.69(6)$ & $8.54(7)$ & \multirow{3}{*}{4.108} & \multirow{3}{*}{0.129} \\
\hline & Overweight & $30.00(48)$ & $17.95(14)$ & $36.58(30)$ & & \\
\hline & Normal & $61.88(99)$ & $74.36(58)$ & $54.88(45)$ & & \\
\hline \multirow{2}{*}{ WC } & Risk & $46.88(75)$ & $15.38(12)$ & $80.49(66)$ & \multirow{2}{*}{27.820} & \multirow{2}{*}{$<0.001$} \\
\hline & Normal & $53.12(85)$ & $84.62(66)$ & $19.51(16)$ & & \\
\hline \multirow{2}{*}{ WHR } & Rísk & $93.75(150)$ & $87.18(68)$ & $97.56(80)$ & \multirow{2}{*}{3.214} & \multirow{2}{*}{.102} \\
\hline & Normal & $6.25(10)$ & $12.82(10)$ & $2.44(2)$ & & \\
\hline \multirow{2}{*}{ WHtR } & Risk & $65.63(105)$ & $51.28(40)$ & $85.37(70)$ & \multirow{2}{*}{14.726} & \multirow{2}{*}{$<0.00$} \\
\hline & Normal & $34.37(55)$ & $48.72(38)$ & $14.63(12)$ & & \\
\hline \multirow{3}{*}{ SBP } & Hypertensive & $37.50(60)$ & $57.69(45)$ & $18.29(15)$ & \multirow{3}{*}{14.344} & \multirow{3}{*}{0.00} \\
\hline & Prehypertensive & $43.75(70)$ & $26.92(21)$ & 70.73(58) & & \\
\hline & Normal & $18.75(30)$ & $15.39(12)$ & $10.98(9)$ & & \\
\hline \multirow{3}{*}{ DBP } & Hypertensive & $56.25(90)$ & $61.00(48)$ & $51.22(42)$ & \multirow{3}{*}{1.125} & \multirow{3}{*}{0.5} \\
\hline & Prehypertensive & $32.50(52)$ & $28.00(22)$ & $39.02(32)$ & & \\
\hline & Normal & $11.25(18)$ & $11.00(9)$ & 9.76.(8) & & \\
\hline \multirow{2}{*}{ Cholesterol } & Risk & $28.12(45)$ & $30.80(24)$ & $26.82(22)$ & \multirow{2}{*}{0.208} & \multirow{2}{*}{0.8} \\
\hline & Normal & $71.88(115)$ & $69.20(54)$ & $73.18(60)$ & & \\
\hline
\end{tabular}




\begin{tabular}{|c|c|c|c|c|c|c|}
\hline \multirow{2}{*}{ Triglyceride } & Risk & $62.50(100)$ & $57.69(45)$ & $67.08(55)$ & \multirow{2}{*}{0.240} & \multirow{2}{*}{0.6} \\
\hline & Normal & $37.50(60)$ & $42.31(33)$ & $32.92(27)$ & & \\
\hline \multirow{2}{*}{ LDL } & Risk & $9.40(15)$ & $2.56(2)$ & $14.63(12)$ & \multirow{2}{*}{3.517} & \multirow{2}{*}{0.1} \\
\hline & Normal & $90.60(145)$ & $97.44(76)$ & $85.37(70)$ & & \\
\hline \multirow{2}{*}{ HDL } & Risk & $31.30(50)$ & $41.02(32)$ & $30.49(25)$ & \multirow{2}{*}{0.890} & \multirow{2}{*}{0.3} \\
\hline & Normal & $68.70(110)$ & $58.98(46)$ & $69.51(57)$ & & \\
\hline \multirow{2}{*}{ TC/HDL ratio } & Risk & $3.75(6)$ & $5.12(4)$ & $2.44(2)$ & \multirow{2}{*}{0.426} & \multirow{2}{*}{0.5} \\
\hline & Normal & $96.25(154)$ & $94.88(74)$ & $97.56(80)$ & & \\
\hline \multirow{2}{*}{$\begin{array}{l}\text { Dyslipidemic (risk } \\
\text { factors) }\end{array}$} & Yes & $25.00(40)$ & $23.00(18)$ & $26.83(22)$ & \multirow{2}{*}{0.104} & \multirow{2}{*}{0.4} \\
\hline & No & $75.00(120)$ & $76.93(60)$ & $73.17(60)$ & & \\
\hline \multirow{2}{*}{ Smoke/tobacco } & Yes & $62.50(100)$ & $55.13(43)$ & $68.29(56)$ & \multirow{2}{*}{1.380} & \multirow{2}{*}{0.2} \\
\hline & No & $37 . .50(60)$ & $44.87(35)$ & $31.71(26)$ & & \\
\hline \multirow{2}{*}{ Family Hostory } & Yes & $50.00(80)$ & $51.28(40)$ & $54.89(45)$ & \multirow{4}{*}{$\begin{array}{l}0.055 \\
9.800\end{array}$} & \\
\hline & No & $50.00(80)$ & $48.72(38)$ & $45.11(37)$ & & \\
\hline \multirow{2}{*}{ Glycemic control } & Yes & $42.50(68)$ & $29.27(24)$ & $41.46(34)$ & & \multirow{2}{*}{0.00} \\
\hline & No & $57.50(92)$ & 70.73.27(54) & $58.54(48)$ & & \\
\hline \multirow{3}{*}{$\begin{array}{l}10 \text {-year } \\
\text { cardiovascular } \\
\text { risk }\end{array}$} & Moderate & $37.50(60)$ & $32.05(25)$ & $46.34(34)$ & \multirow{3}{*}{14.290} & \multirow{3}{*}{0.00} \\
\hline & High & $38.75(62)$ & $55.13(43)$ & $21.95(18)$ & & \\
\hline & Low & $23.75(38)$ & $12.82(10)$ & $31.71(26)$ & & \\
\hline
\end{tabular}

The sex-wise distribution of patients in different categories of cardiovascular risk factors has been presented in Table 2.

The analysis reveals that overall $30 \%$ were overweight, out of which a major proportion was of females (36.58\%) as compared to males $(17.95 \%)$ but the difference was not statistically significant. Central obesity was also more frequent among females (WC-80.49\%, WHtR-85.37\%) than males (WC-15.38\%, WHtR-51.28\%). Considering SBP, $37.50 \%$ were hypertensive and $43.75 \%$ prehypertensive and considering DBP, $56.25 \%$ of the patients were hypertensive and 32.50 were prehypertensive. Significant gender differential was observed for SBP when considered individually with $57.69 \%$ hypertensive males in comparison to $18.29 \%$ hypertensive females and $26.92 \%$ prehypertensive males than $70.73 \%$ prehypertensive females.

The most common risk factors were high triglyceride (62.50\%) followed by low HDL (31.30\%). 25\% of diabetic patients were dyslipidemic. According to the TC/HDL ratio, only $3.75 \%$ of patients were at the risk of cardiovascular diseases. However, no gender differences were found for the risk category of lipid profile. $37.50 \%$ of individuals either smoke or consume tobacco and 50\% have a family history of diabetes.

Females have better glycaemia control $(41.46 \%)$ than males $(29.27 \%)$. The overall estimated risk score for the present population was $21.0(\mathrm{SD} \pm 15.25)$ as shown in Table 1 high risk was found in $38.75 \%$ patients, moderate in $37.50 \%$ patients, and low in $23.75 \%$ patients. Cardiovascular risk showed significant sexual dimorphism with higher proportion of males at high risk
(55.13\%) than females (21.95\%) while $46.34 \%$ of females were at moderate risk as compared to $32 \%$ of male.

Distribution of risk factors and 10 years cardiovascular risk is shown in Table 3 as follows:

Table 3 presents the distribution of risk factors for cardiovascular disease, according to the 10-years cardiovascular risk level that is low, moderate, and high. $32.14 \%$ overweight patients were at high risk and $20 \%$ were at moderate risk for CVD in the next 10 years. The proportion however did not differ significantly from overweight patients (40\%) who are at low risk.

Despite the high frequency of central obese patients, its association with cardiovascular risk level is non significant. Among the patients who had high probability for the incidence of CVD in the future 10 years, $70 \%$ were hypertensive and $23.33 \%$ were prehypertensive while for those with moderate probability, $56.67 \%$ were hypertensive and $36.67 \%$ were prehypertensive. The distribution differed significantly for SBP when it was considered separately from DBP. Major proportion of diabetic patients in the risk category of total cholesterol $(46.67 \%)$ and triglyceride $(70 \%)$ were at high risk as compared to moderate risk $(23.33 \%$ and $70 \%$, resp.). Smoking was also found to be a significant predictor of cardiovascular risk among these patients with $75 \%$ at high risk than $25 \%$ who do not smoke or chew tobacco. On the other hand, $80 \%$ of patients who smoke or chew tobacco were at moderate risk in comparison to $20 \%$ who are nonsmokers or non-tobacco chewer. Other risk factors taken into consideration however did not show any significant results. 
Table 3: Cross tabulation of risk factors and 10-year cardiovascular risk level.

\begin{tabular}{|c|c|c|c|c|c|c|}
\hline \multirow{2}{*}{ Variables } & \multirow{2}{*}{ Categories } & \multicolumn{3}{|c|}{ 10-year cardiovascular risk level } & \multirow{2}{*}{$\begin{array}{l}\text { Chi- } \\
\text { square }\end{array}$} & \multirow{2}{*}{$\begin{array}{l}\text { P- } \\
\text { value }\end{array}$} \\
\hline & & Low & Moderate & High & & \\
\hline \multirow{3}{*}{ BMI } & Underweight & $10.0(4)$ & $6.67(4)$ & $6.5(18)$ & \multirow{3}{*}{2.955} & \multirow{3}{*}{0.562} \\
\hline & Overweight & $40.0(16)$ & $20.0(12)$ & $32.14(18)$ & & \\
\hline & Normal & $50.0(20)$ & $73.33(44)$ & $40.00(24)$ & & \\
\hline \multirow{2}{*}{ WC } & Risk & $65.0(26)$ & $43.33(26)$ & $36.67(22)$ & \multirow{2}{*}{4.372} & \multirow{2}{*}{0.111} \\
\hline & Normal & $35.0(14)$ & $56.67(34)$ & $63.33(38)$ & & \\
\hline \multirow{2}{*}{ WHR } & Risk & $90.0(36)$ & $93.33(56)$ & $96.67(58)$ & \multirow{2}{*}{0.260} & \multirow{2}{*}{0.877} \\
\hline & Normal & $10.0(4)$ & $6.67(4)$ & $3.33(2)$ & & \\
\hline \multirow{2}{*}{ WHtR } & Risk & $75.0(30)$ & $63.33(38)$ & $73.33(44)$ & \multirow{2}{*}{1.910} & \multirow{2}{*}{0.382} \\
\hline & Normal & $25.0(10)$ & $36.67(22)$ & $26.67(16)$ & & \\
\hline \multirow{3}{*}{ SBP } & Prehypertensive & $50.0(20)$ & $53.33(32)$ & $36.67(22)$ & \multirow{3}{*}{21.261} & \multirow{3}{*}{$<0.001$} \\
\hline & Hypertensive & $5.0(2)$ & $33.33(20)$ & $53.33(32)$ & & \\
\hline & Normal & $45.0(18)$ & $13.33(8)$ & $10.00(6)$ & & \\
\hline \multirow{3}{*}{ DBP } & Prehypertensive & $45.0(18)$ & $36.67(22)$ & $23.33(14)$ & \multirow{3}{*}{6.360} & \multirow{3}{*}{0.170} \\
\hline & Hypertensive & $35.0(14)$ & $56.67(34)$ & $70.00(42)$ & & \\
\hline & Normal & $20.0(8)$ & $6.66(4)$ & $6.67(4)$ & & \\
\hline \multirow{2}{*}{ Cholesterol } & Risk & $90.0(36)$ & $76.67(46)$ & $53.33(32)$ & \multirow{2}{*}{7.991} & \multirow{2}{*}{0.018} \\
\hline & Normal & $10.0(4)$ & $23.33(14)$ & $46.67(28)$ & & \\
\hline \multirow{2}{*}{ Triglyceride } & Risk & $55.00(22)$ & $70.00(42)$ & $70.00(42)$ & 6010 & 0050 \\
\hline & Normal & $45.00(18)$ & $30.00(18)$ & $30.00(18)$ & 0.010 & \\
\hline LDL & Risk & $100(40)$ & $93.33(56)$ & $83.33(50)$ & 4.240 & 0.120 \\
\hline & Normal & $0.0(0)$ & $6.67(04)$ & $16.67(10)$ & & \\
\hline HDL & Risk & $70.0(28)$ & $73.30(44)$ & $51.60(32)$ & 3515 & 0171 \\
\hline & Normal & $30.0(12)$ & $26.70(16)$ & $48.40(28)$ & 3.515 & $0.1 / 1$ \\
\hline TC/HDL ratio & Risk & $100(40)$ & $96.67(58)$ & $93.33(56)$ & 1436 & 0.485 \\
\hline 1C/HDL ratio & Normal & $0.0(0)$ & $3.33(2)$ & $6.67(4)$ & 1.450 & 0.485 \\
\hline Dyslinidemic & Yes & $85.00(34)$ & $80.00(48)$ & $63.33(38)$ & 330 & 0.196 \\
\hline Dysmpiaemic & No & $15.00(6)$ & $20.00(12)$ & $36.67(22)$ & 0.50 & 0.190 \\
\hline & Yes & $80.0(32)$ & $80.00(48)$ & $75.00(45)$ & 20359 & $<0.001$ \\
\hline smoke/tobacco & No & $20.0(8)$ & $20.00(12)$ & $25.00(15)$ & 20.559 & $<0.001$ \\
\hline Family history & Yes & $55.00(22)$ & $53.33(32)$ & $62.20(36)$ & 3.488 & 0.174 \\
\hline ramily nistory & No & $45.00(18)$ & $42.4(28)$ & $37.80(24)$ & 5.480 & $0.1 / 4$ \\
\hline Glycemic control & Yes & $40.0(16)$ & $36.40(24)$ & $30.00(18)$ & 4.986 & 0.082 \\
\hline onycemin contror & No & $60.0(24)$ & $63.60(36)$ & $70.00(42)$ & 4.900 & 0.002 \\
\hline & $<5$ years & $28.13(45)$ & $30.00(48)$ & $41.87(93)$ & & \\
\hline Duration & $5-10$ years & $18.75(30)$ & $37.5(60)$ & $43.75(70)$ & 3.871 & 0.422 \\
\hline & $>10$ years & $7.50(12)$ & $33.13(53)$ & $59.37(95)$ & & \\
\hline
\end{tabular}

\section{DISCUSSION}

The present hospital-based study has reported the 10-year risk of developing CVD among type 2 diabetic patients and the probable risk factors. On the basis of the Framingham risk scores, approximately one-third of the subjects recruited for the study will have cardiovascular complications in the next 10 years. Males showed discernible frequency of adverse cardiovascular risk as compared to the females and had higher risk of developing CVD in the future. Similar findings have been reported by Gomes et al among the Brazilian diabetic population, which contradicts with the earlier studies reporting high cardiovascular mortality in women. ${ }^{21-24}$
Recent accumulating evidence has demonstrated that diabetes alters estrogen-related protective mechanism and causes pronounced adverse changes in cardiovascular risk factors leading to enhanced atherogenesis in females. ${ }^{24-26}$ However, a recent meta-analysis showed that although the odds for CVD mortality were higher for women than for men with diabetes, the number of excess deaths attributable to diabetes was higher among men after adjusting for CVD risk factors. ${ }^{27,28}$

The sex differentials in the cardiovascular risk among diabetic patients of central rural India, in present population could be attributed to better glycemic control among females as compared to males. Though the present 
study has not evaluated the direct effect of hyperglycemia on cardiovascular disease, previous literature which includes epidemiological and pathological studies have provided several contradicting findings concerned with detrimental effect of hyperglycemia on cardiovascular risk profile. High blood glucose level leads to oxidative stress and mitochondrial overproduction of superoxide which have been recognized in the pathogenesis of diabetic micro- and macrovascular complications. ${ }^{28-30}$ Clinical trials investigating the efficacy of improving glycemic control have also reported a reduction in the risk of cardiovascular events. ${ }^{29-31}$ However, some recent randomized trials have demonstrated contradicting finding with no significant improvement in cardiovascular risk as a consequence of intensive glucose lowering therapy. ${ }^{32-34}$

The other probable explanation for such biological sex differences in cardiovascular morbidity risk could be the distinct biological as well as gender-related acculturation and lifestyle differences between males and females. ${ }^{35-37}$ Cultural and lifestyle habits have demonstrated stronger influences on metabolic disorders than those from genetic factors. ${ }^{35-37}$ In the present study, males were primarily involved in agriculture and supplement their livelihood by working in governmental and private sectors while the majority of the females were homemakers. The gender difference in lifestyle depends on the sex-specific behaviour inculcated in an individual by family or society in which they live and it varies with age.

The elevated risk of cardiovascular events among diabetic versus non-diabetic patients emphasizes screening asymptomatic diabetic patients for CVD risk. It is based on the premise that earlier identification and stratification would lead to appropriate management of cardiovascular risk for both long term $(>10$ years) and short term ( $\leq 10$ years). In the present study, $59.37 \%$ of patients were at high risk, $33.13 \%$ at moderate risk, and $7.50 \%$ at low risk for developing CVD in the next 10 years according to the Framingham risk score. Systolic blood pressure, total cholesterol, triglyceride, and smoking have contributed significantly to the high risk of developing CVD in the future among these patients, which are already distinguished as risk factors for CVD. Obesity (regional and central) despite being a prominent risk marker in this population has not significantly predicted the cardiovascular risk as assessed by the Framingham risk score. This is in contrast to the earlier studies which have reported regional adiposity markers to be the predictor of cardiovascular risk..$^{37-39}$ This finding indicates the pioneer role of metabolic risk factors in the causation of disease among otherwise normal weight or obese patients. These identified risk factors have been reported as potential predictors among both diabetic and nondiabetic. ${ }^{40}$ However, at every level of risk factor, diabetic subjects have twofold higher risk, and the risk for disease increases over time with the accumulation of unfavourable metabolic factors. ${ }^{40,41}$
Furthermore, in this study group, a large fraction of patients $(61 \%)$ had uncontrolled fasting sugar, which could be accredited to the potato and rice intake, a staple diet of the population in the present study. Rice and potato rich in carbohydrate, have a high glycemic index (GI) which relates to the increased cardiovascular risk. The role of carbohydrates as a risk factor depends on their type; a high consumption of carbohydrates from high-GI foods rather than low-GI foods influences the risk of developing CVD. ${ }^{41-43}$ The glycemic index value of white rice also depends on the degree of processing, cooking time, and amylose content, but still is higher on average than that of whole grains. ${ }^{43,44}$ These findings are in agreement with the other prospective study, which has reported high dietary GI to be associated with increased CVD risk. ${ }^{4.45}$ A study has found that restricted diet of diabetics has contributed significantly to the lower amount of zinc and magnesium in rural central India. ${ }^{46,47}$ Deficiency of these trace elements has been associated with increased incidence of cardiovascular disease and other diabetic complications. ${ }^{47,48}$ However, more studies probing such aspect of dietary components in relation to cardiometabolic diseases are needed.

Primary prevention through improved control of risk factors and therapeutic lifestyle modification (including dietary modification, aerobic exercise and smoking cessation) is a pioneer strategy advocated by the National Cholesterol Education Program in the Adult Treatment Panel III (ATP III) guidelines. ${ }^{10-12}$ Lifestyle interventions have been effective in the improvement of cardiovascular risk factors and the benefits are proportionally higher among those at high risk for cardiovascular disease. ${ }^{46-48}$ However, the paradox in the prevention of cardiovascular complications of type 2 diabetes is that, at diagnosis, diabetic individuals are already at an amplified risk of CVD. 47,48 "Ticking clock" hypothesis postulates that the clock for coronary heart disease starts ticking before the onset of clinical diabetes. ${ }^{45,46,48}$ It can also be attuned with the "common soil" hypothesis which postulates that both diabetes and CVD have common genetic and environmental antecedents. Furthermore, insulin resistance preceding long before the diagnosis of diabetes enhances atherogenic risk profile and has been delineated as a potential cause for subsequent increased risk of CVD among diabetic patients. ${ }^{46-48}$ This mounting evidence accentuates the need of intensive management of cardiovascular risk factors among diabetic individuals. Therefore, there is a need of a comprehensive study design which includes various factors (biological, sociodemographic and genetic) which directly or indirectly influence the disease incidence especially in a country with a diverse ethnic population.

\author{
Funding: No funding sources \\ Conflict of interest: None declared \\ Ethical approval: Not required
}




\section{REFERENCES}

1. Haffner SM, Lehto S, Rönnemaa T, Pyörälä K, Laakso M. Mortality from coronary heart disease in subjects with type 2 diabetes and in nondiabetic subjects with and without prior myocardial infarction. N Engl J Med. 1998;339(4):229-34.

2. Grundy SM, Benjamin IJ, Burke GL, Chait A, Eckel $\mathrm{RH}$, Howard BV, et al. AHA scientific statement, diabetes and cardiovascular disease: a statement for healthcare professionals from the American Heart Association. Circulation. 1999;100:1134-46.

3. Lloyd-Jones DM, Wilson PW, Larson MG, Beiser A, Leip EP, D'Agostino RB, et al. Framingham risk score and prediction of lifetime risk for coronary heart disease. Am J Cardiol. 2004;94(1):20-4.

4. Grundy SM, Balady GJ, Criqui MH, Fletcher G, Greenland P, Hiratzka LF, et al. Primary prevention of coronary heart disease: guidance from Framingham: a statement for healthcare professionals from the AHA task force on risk reduction. American Heart Association. Circulation. 1998;97(18):1876-87.

5. Conroy RM, Pyörälä K, Fitzgerald AP, Sans S, Menotti A, De Backer G, et al. Estimation of tenyear risk of fatal cardiovascular disease in Europe: the SCORE project. Eur Heart J. 2003;2(11):9871003.

6. Ridker PM, Buring JE, Rifai N, Cook NR. Development and validation of improved algorithms for the assessment of global cardiovascular risk in women: the Reynolds Risk Score. JAMA. 2007;297(6):611-9.

7. Hippisley-Cox J, Coupland C, Vinogradova Y, Robson J, Minhas R, Sheikh A, et al. Predicting cardiovascular risk in England and Wales: prospective derivation and validation of QRISK2. BMJ. 2008;336(7659):1475-82.

8. Beswick A, Brindle P. Risk scoring in the assessment of cardiovascular risk. Curr Opin Lipidol. 2006;17(4):375-86.

9. Census of India, Provisional population table, 2011, American Diabetes Association, Standards of medical care in diabetes. Diabetes Care. 2005;28(1):5-36.

10. Weiner JS, Lourie JA, eds. Practical human biology. London: Academic Press; 1981.

11. World Health Organization. Diet, Nutrition and the Prevention of Chronic Disease: Report of a Joint WHO/FAO Expert Consultation. Geneva, Switzerland: World Health Organization. WHO Technical Report Series; 2003:916.

12. Ashwell OBE M. Waist to height ratio and the Ashwell shape chart to predict the health risks of obesity in adults and children in all ethnic groups. The Journal of Nutrition and Food Science. 2005;35(5):359-64.

13. Pickering TG, Hall JE, Appel LJ, Falkner BE, Graves JW, Hill MN, et al. Recommendations for blood pressure measurement in humans: an AHA scientific statement from the Council on High Blood Pressure Research Professional and Public Education Subcommittee. The Journal of Clinical Hypertension. 2005;7(2):102-9.

14. Chobanian AV, Bakris GL, Black HR, Cushman WC, Green LA, Izzo Jr JL, et al. The seventh report of the joint national committee on prevention, detection, evaluation, and treatment of high blood pressure: the JNC 7 report. JAMA. 2003;289(19):2560-71.

15. American Diabetes Association. Standards of medical care in diabetes- 2012. Diabetes Care. 2012;35:S11-63.

16. D'Agostino RB, Vasan RS, Pencina MJ, Wolf PA, Cobain M, Massaro JM, et al. General cardiovascular risk profile for use in primary care. Circulation. 2008;117(6):743-53.

17. Gomes MB, Giannella-Neto D, Faria M, Tambascia M, Fonseca RM, Rea R, et al. Estimating cardiovascular risk in patients with type 2 diabetes: a national multicenter study in Brazil. Diabetol Metabol Syndrome. 2009;1(1):22-8.

18. Lee WL, Cheung AM, Cape D, Zinman B. Impact of diabetes on coronary artery disease in women and men: a meta-analysis of prospective studies. Diabetes Care. 2000;23(7):962-8.

19. Hu G, Jousilahti P, Qiao Q, Katoh S, Tuomilehto J. Sex differences in cardiovascular and total mortality among diabetic and non-diabetic individuals with or without history of myocardial infarction. Diabetol. 2005;48(5):856-61.

20. Steinberg HO, Paradisi G, Cronin J, Crowde K, Hempfling A, Hook G, et al. Type II diabetes abrogates sex differences in endothelial function in premenopausal women. Circulation. 2000;101(17):2040-6.

21. Juutilainen A, Kortelainen S, Lehto S, Rönnemaa T, Pyörälä K, Laakso M. Gender difference in the impact of type 2 diabetes on coronary heart disease risk. Diabetes Care. 2004 ;27(12):2898-904.

22. Kanaya AM, Grady D, Barrett-Connor E. Explaining the sex difference in coronary heart disease mortality among patients with type 2 diabetes mellitus: a meta-analysis. Archives of Internal Med. 2002;162(15):1737-45.

23. Laakso M. Cardiovascular disease in type 2 diabetes from population to man to mechanisms. Diabetes Care. 2010;33(2):442-9.

24. UK Prospective Diabetes Study (UKPDS) Group. Intensive blood-glucose control with sulphonylureas or insulin compared with conventional treatment and risk of complications in patients with type 2 diabetes (UKPDS 33). The lancet. 1998;352(9131):837-53.

25. Dormandy JA, Charbonnel B, Eckland DJ, Erdmann E, Massi-Benedetti M, Moules IK, et el. Secondary prevention of macrovascular events in patients with type 2 diabetes in the PROactive Study (PROspective pioglitAzone Clinical Trial In 
macroVascular Events): a randomised controlled trial. The Lancet. 2005;366(9493):1279-89.

26. Mannucci E, Monami M, Lamanna C, Gori F, Marchionni N. Prevention of cardiovascular disease through glycemic control in type 2 diabetes: a metaanalysis of randomized clinical trials. Nutrition, Metabolism and Cardiovascular Diseases. 2009;19(9):604-12.

27. ADVANCE Collaborative Group. Intensive blood glucose control and vascular outcomes in patients with type 2 diabetes. $\mathrm{N}$ Engl $\mathrm{J}$ Med. 2008;2008(358):2560-72.

28. Action to Control Cardiovascular Risk in Diabetes Study Group. Effects of intensive glucose lowering in type 2 diabetes. $\mathrm{N}$ Engl $\mathrm{J}$ Med. 2008;2008(358):2545-59.

29. Duckworth W, Abraira C, Moritz T, Reda D, Emanuele N, Reaven PD, et al. Glucose control and vascular complications in veterans with type 2 diabetes. New England J Med. 2009;360(2):129-39.

30. Ahmad Kiadaliri A, Clarke PM, Gerdtham UG, Nilsson P, Eliasson B, Gudbjörnsdottir S, et al. Predicting changes in cardiovascular risk factors in type 2 diabetes in the post-UKPDS era: longitudinal analysis of the Swedish National Diabetes Register. J Diabetes Res. 2013;2013(55)1050-6.

31. Chiu JF, Bell AD, Herman RJ, Hill MD, Stewart JA, Cohen EA, et al. Cardiovascular risk profiles and outcomes of Chinese living inside and outside China. European J Cardio Prev Rehabilit. 2010;17(6):668-75.

32. Dhall M, Gupta S, Bhuker M, Sharma P, Kapoor S. Effectiveness of various anthropometric indices in prediction of cardiovascular risk among adult Jains. The Open Anthropology Journal. 2011;4(13):33-9.

33. Czernichow S, Kengne AP, Huxley RR, Batty GD, De Galan B, Grobbee D, et al. Comparison of waistto-hip ratio and other obesity indices as predictors of cardiovascular disease risk in people with type-2 diabetes: a prospective cohort study from ADVANCE. European Journal of Cardiovascular Prevention Rehabilitation. 2011;5(2):312-9.

34. Bhasin P, Kapoor S. Pregnancy complications and calculated cardiovascular risk in urban women: do we envisage an association? Journal of Urban Health. 2014;91(1):162-75.

35. Stamler J, Vaccaro O, Neaton JD, Wentworth D, Multiple risk factor intervention trial research group. Diabetes, other risk factors, and 12-yr cardiovascular mortality for men screened in the Multiple Risk Factor Intervention Trial. Diabetes Care. 1993;16(2):434-44.

36. Smith SC Jr. Multiple risk factors for cardiovascular disease and diabetes mellitus. Am J Med. 2007;120(3 Suppl 1):S3-11.

37. Foster-Powell K, Holt SH, Brand-Miller JC. International table of glycemic index and glycemic load values: Am J Clin Nut. 2002;76(45):50-6.
38. Levitan EB, Mittleman MA, Håkansson N, Wolk A. Dietary glycemic index, dietary glycemic load, and cardiovascular disease in middle-aged and older Swedish men. Am J Clin Nutr. 2007;85(6):1521-6.

39. Key TJ, Fraser GE, Thorogood M, Appleby PN, Beral V, Reeves G, et al. Mortality in vegetarians and nonvegetarians: detailed findings from a collaborative analysis of 5 prospective studies. The Am J Clin Nutrit. 1999;70(3):516-24.

40. Chakraborty R, Dey S, Dkhar P, Thabah C, Rynjah W. Diabetics of Northeast India are at risk of dietary Zinc and Manganese deficiency: Possible improvement through consumption of some traditional edibles or edibles of limited popularity. Internat J Diab Develop Countries. 2010;30(4):2017.

41. Anetor JI, Senjobi A, Agbedana EO, Ajose OA. Decreased serum magnesium and zinc levels: atherogenic implications in type-2 diabetes mellitus in Nigerians. Nutrition and health. 2002;16(4):291300 .

42. Watkins PJ. ABC of diabetes: cardiovascular disease, hypertension, and lipids. British Med J. 2003;326(7394):874-6.

43. Laakso M. Epidemiology of macrovascular disease in diabetes. Diabetes Rev. 1997;5(20)294-315.

44. Haffner SM, Stern MP, Hazuda HP, Mitchell BD, Patterson JK. Cardiovascular risk factors in confirmed prediabetic individuals: does the clock for coronary heart disease start ticking before the onset of clinical diabetes. JAMA. 1990;263(21):2893-900.

45. Eddy D, Schlessinger L, Kahn R, Peskin B, Schiebinger R. Relationship of insulin resistance and related metabolic variables to coronary artery disease: a mathematical analysis. Diabetes Care. 2009;32(2):361-6.

46. Laakso M. Cardiovascular disease in type 2 diabetes from population to man to mechanisms. Diabetes Care. 2010;33(2):442-9.

47. UK Prospective Diabetes Study (UKPDS) Group. Intensive blood-glucose control with sulphonylureas or insulin compared with conventional treatment and risk of complications in patients with type 2 diabetes (UKPDS 33). The Lancet. 1998;352(9131):837-53.

48. Anetor JI, Senjobi A, Agbedana EO, Ajose OA. Decreased serum magnesium and zinc levels: atherogenic implications in type-2 diabetes mellitus in Nigerians. Nutrition Health. 2002;16(4):291-300.

49. Watkins PJ. ABC of diabetes: cardiovascular disease, hypertension and lipids. British Med J. 2003;326(7394):874-6.

Cite this article as: Singh PS, Zafar KS, Kumar M, Yadav SK. Risk of cardiovascular disease among diabetic patients in rural population of Central India. Int J Res Med Sci 2017;5:1563-70. 